\title{
Phase I study of liposomal irinotecan in patients with metastatic breast cancer: findings from the expansion phase
}

\author{
Jasgit C. Sachdev ${ }^{1,2}$ (D) Pamela Munster ${ }^{3} \cdot$ Donald W. Northfelt ${ }^{4} \cdot$ Hyo Sook Han ${ }^{5} \cdot$ Cynthia Ma $^{6} \cdot$ Fiona Maxwell $^{7}$. \\ Tiffany Wang $^{8} \cdot$ Bruce Belanger $^{8} \cdot$ Bin Zhang $^{8} \cdot$ Yan Moore $^{8} \cdot$ Arunthathi Thiagalingam $^{8} \cdot$ Carey Anders $^{9}$
}

Received: 15 July 2020 / Accepted: 20 October 2020 / Published online: 17 November 2020

(c) The Author(s) 2020

\begin{abstract}
Purpose Metastatic breast cancer $(\mathrm{mBC})$ remains incurable and is associated with low survival rates. This study assessed the efficacy and safety of liposomal irinotecan in heavily pretreated patients with $\mathrm{mBC}$, with or without active brain metastases (BM).

Methods Following the dose escalation phase and determination of recommended phase 2 dose, the expansion phase of this phase I, open-label, non-randomized study, assigned adult women to cohorts based on $\mathrm{mBC}$ subtype: cohort 1, hormone receptor +/human epidermal growth factor receptor 2-; cohort 2, triple-negative breast cancer; or cohort 3, any mBC subtype with active BM. Patients received liposomal irinotecan 50 or $70 \mathrm{mg} / \mathrm{m}^{2}$ free base every 2 weeks. Here, we report secondary outcomes including best overall response (BOR), objective response rate (ORR), and treatment-emergent adverse events (TEAEs).

Results For non-central nervous system (non-CNS) disease across all cohorts (intent-to-treat population, $N=29$ ), the ORR was 34.5\% (95\% confidence interval: 17.94-54.33), with a BOR of partial response in 10 patients (34.5\%), stable disease in five (17.2\%), progressive disease in 10 (34.5\%); four patients were unevaluable (13.8\%). The ORR for the CNS cohort was 30.0\% (95\% confidence interval: 6.67-65.25) using modified Response Evaluation Criteria in Solid Tumors. Common grade 3 or higher TEAEs were diarrhea (27.6\%), nausea (17.2\%), fatigue (13.8\%), asthenia (10.3\%), and hypokalemia (10.3\%). Serious treatment-related TEAEs were reported in six patients $(20.7 \%)$. No treatment-related TEAEs resulted in death.

Conclusions Liposomal irinotecan monotherapy demonstrated antitumor activity in heavily pretreated patients with $\mathrm{mBC}$, with or without BM. The observed safety profile was consistent with that in previous studies.
\end{abstract}

Clinical trial registration: Trial registration ID NCT01770353.

Keywords Liposomal irinotecan $\cdot$ Metastatic breast cancer $\cdot$ Objective response rate $\cdot$ Phase I clinical trial $\cdot$ Brain metastases $\cdot$ Heavily pretreated patients

\section{Introduction}

An estimated 276,480 women in the USA are predicted to be diagnosed with invasive breast cancer in 2020 [1]. Despite recently improved outcomes, the 5-year survival rate for women with metastatic breast cancer $(\mathrm{mBC})$ in the USA remains low at $27 \%$ [1]. The estimated incidence of brain

Electronic supplementary material The online version of this article (https://doi.org/10.1007/s10549-020-05995-7) contains supplementary material, which is available to authorized users.

Jasgit C. Sachdev

Jasgit.Sachdev@HonorHealth.com

Extended author information available on the last page of the article metastases (BM) in patients with $\mathrm{mBC}$ is $24 \%$; the estimated survival time of patients with BM is 15 months from diagnosis. BM are associated with morbidity and negatively impact functional status and quality of life [2]. Because women with $\mathrm{mBC}$ are living longer, cases of $\mathrm{BM}$ are expected to increase.

Systemic treatments for $\mathrm{mBC}$ are selected based on multiple factors, including age, comorbidities, hormone receptor and human epidermal growth factor receptor 2 (HER2) status, previous cancer treatments, and tumor burden [3]. In patients with $\mathrm{mBC}$ and $\mathrm{BM}$, systemic treatments have limited central nervous system (CNS) efficacy, and disease progression after localized treatment(s) (i.e., whole brain radiation therapy, stereotactic radiosurgery, and/or surgical resection) presents a significant clinical challenge [2]. 
Currently, tucatinib, in combination with trastuzumab and capecitabine, is the only systemic therapy approved by the Food and Drug Administration (FDA) for the treatment of adult patients with advanced unresectable or metastatic HER2+ breast cancer, including patients with BM, who have received one or more prior anti-HER2-based regimens in the metastatic setting [4].

The anticancer prodrug irinotecan has a mechanism of action that is distinct from other medications used for $\mathrm{mBC}$ treatment; therefore, the risk of cross-resistance from previous cancer therapies is considered low. The active metabolite of irinotecan, $\mathrm{SN}-38$, reversibly binds to the topoisomerase I-DNA complex and prevents religation of single-strand breaks, leading to double-strand DNA damage and cell death [5]. Irinotecan can cross the blood-brain barrier and has shown promising results for BM treatment in two phase II studies; one in primary CNS tumors [6] and another in triple-negative breast cancer (TNBC) when administered with iniparib [7].

Liposomal irinotecan (ONIVYDE®; Ipsen Biopharmaceuticals, Inc.; historical names include nal-IRI, MM-398, or PEP02) is an intravenously delivered formulation [5]; individual liposomes have a diameter of approximately $110 \mathrm{~nm}$ [8], which is close to the nanoscale $(1-100 \mathrm{~nm})$ [9]. Liposomal encapsulation increases the nominal plasma halflife of irinotecan [10]. Deposition in tumor lesions occurs through leaky vasculature within the lesion via the enhanced permeability and retention (EPR) [11] effect before conversion of the payload to SN-38 [12]. Liposomal irinotecan is approved, in combination with 5-fluorouracil and leucovorin, for the treatment of patients with metastatic pancreatic ductal adenocarcinoma (mPDAC) following progression with gemcitabine-based therapy [5]. Preclinical data suggest that liposomal irinotecan may have utility as a treatment for $\mathrm{mBC}$ with $\mathrm{BM}$ [13].
To investigate this potential activity in heavily pretreated patients with $\mathrm{mBC}$, including active $\mathrm{BM}$, we report efficacy and safety outcomes from the expansion phase of a phase I cross-indication translational study (ClinicalTrials.gov identifier: NCT01770353).

\section{Methods}

\section{Study design}

This multicenter, non-comparative, open-label, non-randomized, phase I study was conducted in the USA between November 19, 2012 (first patient, first visit) and October 2, 2018 (last patient, last visit). The study comprised a pilot phase followed by an expansion phase (Fig. 1). The pilot phase was previously reported by Ramanathan et al. [14]. The expansion phase was conducted in patients with $\mathrm{mBC}$ (first liposomal irinotecan dose in first patient, May 18, 2015), and the primary outcome was to investigate ferumoxytol quantitation in tumor lesions (to be reported elsewhere).

Here, we report secondary outcomes from the expansion phase: the efficacy and safety of liposomal irinotecan in adult patients with $\mathrm{mBC}$, including active BM.

\section{Expansion phase population}

Adult women aged $\geq 18$ years were recruited into three cohorts (target 10 patients per cohort) based on historical archival receptor subtyping: cohort 1, estrogen receptor $(\mathrm{ER})+$ and/or progesterone receptor $(\mathrm{PgR})+/ \mathrm{HER} 2-$; cohort 2, ER - and PgR-/HER2- (TNBC); or cohort 3, any $\mathrm{mBC}$ subtype with active $\mathrm{BM}(\mathrm{mBCBM})$. In cohort 3 , patients were required to have radiographic evidence of new or progressive $\mathrm{BM}$ after radiation therapy with $\geq 1$ lesion

Fig. 1 Study design. $B M$ brain metastases, $E R$ estrogen receptor, HER2 human epidermal growth factor receptor $2, m B C$ metastatic breast cancer, $P g R$ progesterone receptor, $T N B C$ triple-negative breast cancer

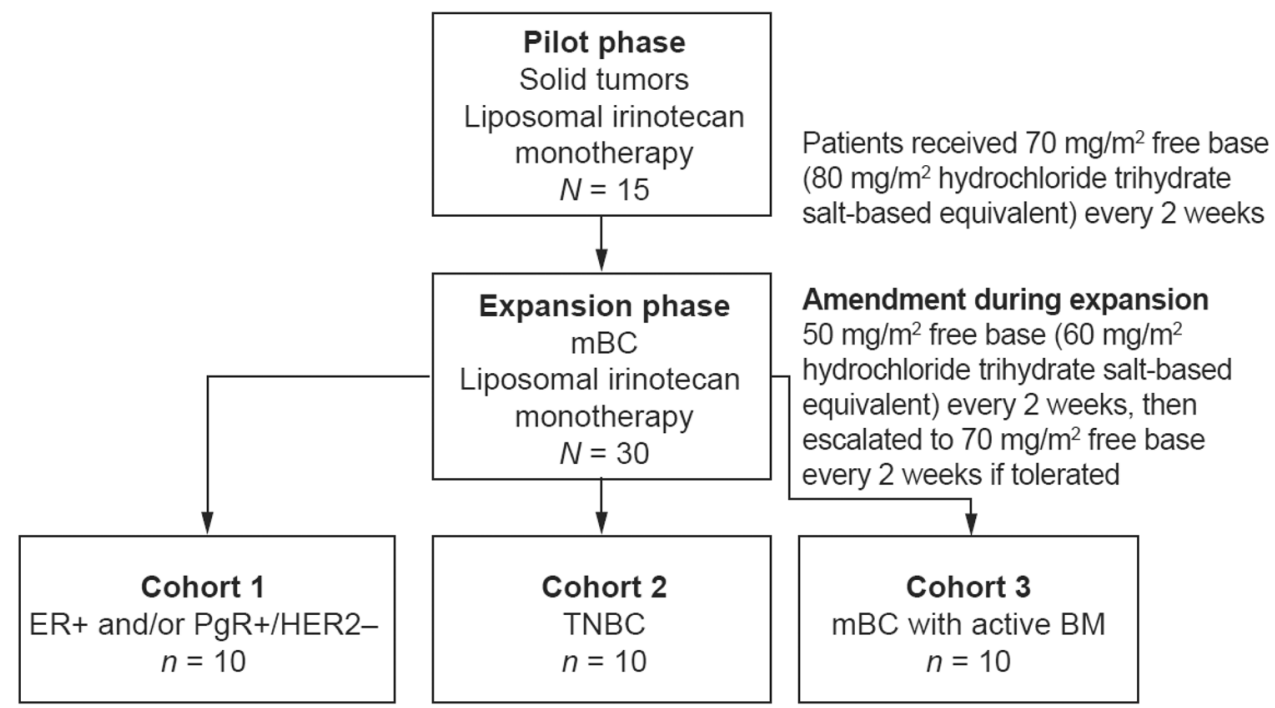


measuring $\geq 1 \mathrm{~cm}$ in the longest dimension on gadoliniumenhanced MRI, and to be considered neurologically stable. In all cohorts, key inclusion criteria included locally advanced or metastatic disease with $\geq 2$ radiologically measurable lesions; an Eastern Cooperative Oncology Group performance status of 0 or 1; adequate bone marrow reserves, and adequate hepatic and renal function; and 1-5 prior lines of chemotherapy in the metastatic setting. Patients with active CNS metastases were excluded from cohorts 1 and 2. See Supplementary Table S1 for full inclusion and exclusion criteria, including those specifically relating to patients with BM.

\section{Expansion phase treatment}

On day 1 , patients received a single dose of intravenous ferumoxytol $5 \mathrm{mg} / \mathrm{kg}$ infused over $15 \mathrm{~min}$, used here as a magnetic resonance imaging (MRI) lesion-imaging agent (reported elsewhere) $[14,15]$. Within 7 days after ferumoxytol infusion, patients received their first dose of intravenous liposomal irinotecan $70 \mathrm{mg} / \mathrm{m}^{2}$ free base, infused over $90 \mathrm{~min}$. Extracranial biopsies from a single lesion were acquired either prior to dosing with liposomal irinotecan or approximately $72 \mathrm{~h}$ after the first dose. Subsequent doses of liposomal irinotecan were administered every 2 weeks ( \pm 2 days). Protocol Amendment 4 (November 3, 2016) reduced the starting dose to $50 \mathrm{mg} / \mathrm{m}^{2}$ free base, with allowance for escalation to $70 \mathrm{mg} / \mathrm{m}^{2}$ free base, depending on patient tolerance.

In all cohorts, treatment continued until disease progression was observed (as assessed using Response Evaluation Criteria in Solid Tumors [RECIST] v1.1 criteria), unacceptable tolerability had occurred, or consent was withdrawn. In cohorts 1 and 2 , treatment could continue in patients with radiographic disease progression without symptomatic deterioration if they had derived clinical benefit, based on a consensus between the investigator, medical monitor, and sponsor. In cohort 3, CNS and non-CNS disease were assessed separately, and treatment was discontinued in patients with radiographic evidence of CNS disease progression. Treatment continuation was permitted, at the investigator's discretion, in patients with non-CNS disease progression in the absence of CNS disease progression. Cohort 3 patients with symptomatic CNS disease progression but without radiographic confirmation were permitted to continue treatment.

During the study, all concurrent medical conditions and complications of the underlying malignancy could be treated at the discretion of the investigator, according to acceptable local standards of medical care. Patients could receive analgesics, antiemetics, antibiotics, anti-pyretics, and blood products as deemed necessary. Further details of concomitant therapy are provided in supplementary materials. Information on post-trial treatments was not collected.

\section{Efficacy assessments}

Efficacy assessments were included in the expansion phase as secondary study endpoints; primary endpoints did not include efficacy and will be reported elsewhere. Tumor assessments, both non-CNS (all cohorts) and CNS (cohort 3 only) by computed tomography (CT) or magnetic resonance imaging, were performed at baseline and at 8-week intervals. RECIST v1.1 and modified RECIST (Supplementary Table S2) were utilized to assess nonCNS systemic disease and CNS disease, respectively. To be considered evaluable, patients were required to have received liposomal irinotecan and to have completed at least one CT scan at the 8-week post-treatment time point. For post-baseline assessments, overall tumor response was classified as complete response (CR), partial response (PR), stable disease (SD), progressive disease (PD), or not evaluable (NE). A non-CR/non-PD was also available for non-target lesions. Based on tumor response assessments, additional efficacy outcomes included best overall response (BOR), objective response rate (ORR), clinical benefit rate (CBR; defined as CR or PR, and SD lasting at least 24 weeks), duration of objective response (DOR), and progression-free survival (PFS); definitions are provided in supplementary materials.

\section{Safety assessments}

All treatment-emergent adverse events (TEAEs) were recorded using National Cancer Institute Common Terminology Criteria for Adverse Events (NCI CTCAE) version 4.02. Final safety assessments were completed 30 days ( \pm 7 days) after the patient received their last dose of liposomal irinotecan.

\section{Metastatic tumor receptor status-exploratory, post hoc analyses}

See Supplementary Materials for details of retrospective analyses of metastatic tumor receptor status for on-study biopsy materials.

\section{Statistical analysis}

All patients who received at least one dose of liposomal irinotecan were included in the liposomal irinotecan safety population. The liposomal irinotecan efficacy population comprised all patients who received liposomal irinotecan and had evaluable efficacy data. No formal hypothesis testing was performed; therefore, this study was not powered to 
detect statistical differences in any parameter. Descriptive results are reported.

\section{Results}

\section{Patients}

A patient disposition flowchart is provided in Supplementary Fig. S1. In total, 30 patients (10 per cohort) were enrolled in the expansion phase (Table 1). All enrolled patients were women with a median age of 53 (range 29-70) years. In each cohort, most patients were white, and most were heavily pretreated with a median of three (range 0-6) prior cytotoxic anticancer regimens in the metastatic setting.

The safety population comprised 29 patients who had received at least one dose of liposomal irinotecan. All these patients had evaluable efficacy data and comprised the liposomal irinotecan efficacy population. One patient enrolled in cohort 2 (TNBC) died owing to PD before receiving liposomal irinotecan and was not included in the liposomal irinotecan safety or efficacy analyses.

In total, 13 patients initiated liposomal irinotecan at $70 \mathrm{mg} / \mathrm{m}^{2}$ free base, and 15 patients initiated at $50 \mathrm{mg} /$ $\mathrm{m}^{2}$ free base. One patient initiated liposomal irinotecan at $35 \mathrm{mg} / \mathrm{m}^{2}$ free base based on the investigator's clinical decision and their UGT1A $1 * 28$ allele homozygous polymorphism. Median exposure to liposomal irinotecan among all patients was 12.3 (range 0.1-105.3) weeks. All patients had discontinued the study by week 114 (Fig. 2). Reasons for discontinuation of liposomal irinotecan were PD radiographically confirmed as per RECIST v1.1 (18 patients, 62.1\% [percentages rounded]), other (seven patients, 24.1\%), investigator decision (three patients, 10.3\%), and TEAEs (one patient, 3.4\%). 'Other' was an option on the electronic case report form and included clinical deterioration or clinical PD in six patients, and toxicity-related diarrhea and clinical $\mathrm{PD}$ in one patient.

\section{Efficacy}

\section{Response to treatment}

The BOR for non-CNS disease across all cohorts was PR in ten patients $(34.5 \%)$, SD in five patients $(17.2 \%)$, and $\mathrm{PD}$ in ten patients (34.5\%); four patients (13.8\%) were NE (Table 2). No patients had a CR. The BOR was: cohort 1 (ER+ and/or PgR+/HER2-), PR in 40.0\%, and PD in $50.0 \%$, with one patient NE; cohort 2 (TNBC), PR in 33.3\%, $\mathrm{SD}$ in $33.3 \%$, and $\mathrm{PD}$ in $22.2 \%$, with one patient $\mathrm{NE}$; cohort 3 (mBCBM) for non-CNS disease, $\mathrm{PR}$ in $30.0 \%$, SD in $20.0 \%$, and PD in $30.0 \%$, with two patients NE. For nonCNS disease across all cohorts, both the ORR and the CBR were $34.5 \%$ (Table 2). For CNS disease in cohort 3, the BOR was PR in $30.0 \%$, SD in $30.0 \%$, and PD in $20.0 \%$, with two patients NE, and the ORR and CBR were $30.0 \%$ and $50.0 \%$, respectively (Table 2).

Table 1 Demographics and baseline characteristics (ferumoxytol safety population, $N=30$ )

\begin{tabular}{|c|c|c|c|c|}
\hline & $\begin{array}{l}\text { Cohort } 1 \\
(n=10)\end{array}$ & $\begin{array}{l}\text { Cohort } 2 \\
(n=10)\end{array}$ & $\begin{array}{l}\text { Cohort } 3^{\mathrm{a}} \\
(n=10)\end{array}$ & $\begin{array}{l}\text { Total population } \\
(N=30)\end{array}$ \\
\hline Sex, female, $n(\%)$ & $10(100)$ & $10(100)$ & $10(100)$ & $30(100)$ \\
\hline Age, years, median (range) & $56.0(49-68)$ & $52.5(37-70)$ & $45.5(29-63)$ & $53.0(29-70)$ \\
\hline \multicolumn{5}{|l|}{ Race, $n(\%)$} \\
\hline White & $8(80.0)$ & $8(80.0)$ & $7(70.0)$ & $23(76.7)$ \\
\hline Black or African American & 0 & $1(10.0)$ & $1(10.0)$ & $2(6.7)$ \\
\hline American Indian or Native Alaskan & 0 & 0 & 0 & 0 \\
\hline Asian & $1(10.0)$ & 0 & $1(10.0)$ & $2(6.7)$ \\
\hline Native Hawaiian or other Pacific islander & $1(10.0)$ & 0 & 0 & $1(3.3)$ \\
\hline Other & 0 & $1(10.0)$ & $1(10.0)$ & $2(6.7)$ \\
\hline Time since metastatic diagnosis, months, median (range) & $63.7(16-87)$ & $20.7(0-34)$ & $32.4(8-55)$ & $24.0(0-87)$ \\
\hline Number of prior cytotoxic anticancer regimens, median (range) & $3.0(1-6)$ & $3.0(0-5)$ & $3.0(1-6)$ & $3.0(0-6)$ \\
\hline
\end{tabular}

Percentages are subject to rounding

$B M$ brain metastases, $E R$ estrogen receptor, $H E R 2$ human epidermal growth factor receptor $2, m B C$ metastatic breast cancer, $P g R$ progesterone receptor, $T N B C$ triple-negative breast cancer

${ }^{a}$ Four patients had TNBC; three patients were ER+ and/or PgR+/HER2+, two patients were ER+ and/or PgR+/HER2-, and one patient was ER- and/or PgR-/HER2+. Of the four patients with HER2+ mBC based on pre-study biopsies, three had received HER2 blockade prior to study entry. The patient who had not received prior HER2 blockade had TNBC before their diagnosis of BM. Brain tissue biopsy from this patient showed ER+ HER2+ tissue. At diagnosis of BM, after surgery, radiotherapy and letrozole, the patient had stable BM and was subsequently enrolled in the expansion phase of the present clinical trial 
Fig. 2 Response to liposomal irinotecan over time until treatment discontinuation (liposomal irinotecan efficacy population, $n=29$ ). Individual doses of liposomal irinotecan are displayed above each patient's treatment timeline, and the values depict a $35,43,50$, or $70 \mathrm{mg} / \mathrm{m}^{2}$ free base intravenous infusion. One patient in cohort 2 was enrolled but discontinued before receiving treatment. Patient death is depicted by an ' $\mathrm{X}$ '. $A E$ adverse event, $B M$ brain metastases, CLIN clinical, CNS central nervous system, $D E T$ deterioration, ER estrogen receptor, HER 2 human epidermal growth factor receptor 2, $I N V D E C$ investigator decision, $m B C$ metastatic breast cancer, $P D$ progressive disease, $P g R$ progesterone receptor, $P R$ partial response, RECIST Response Evaluation Criteria in Solid Tumors, $S D$ stable disease, $T N B C$ triple-negative breast cancer, TOX toxicity a Cohort 1: patients with ER+ and/or PgR+/HER2- mBC

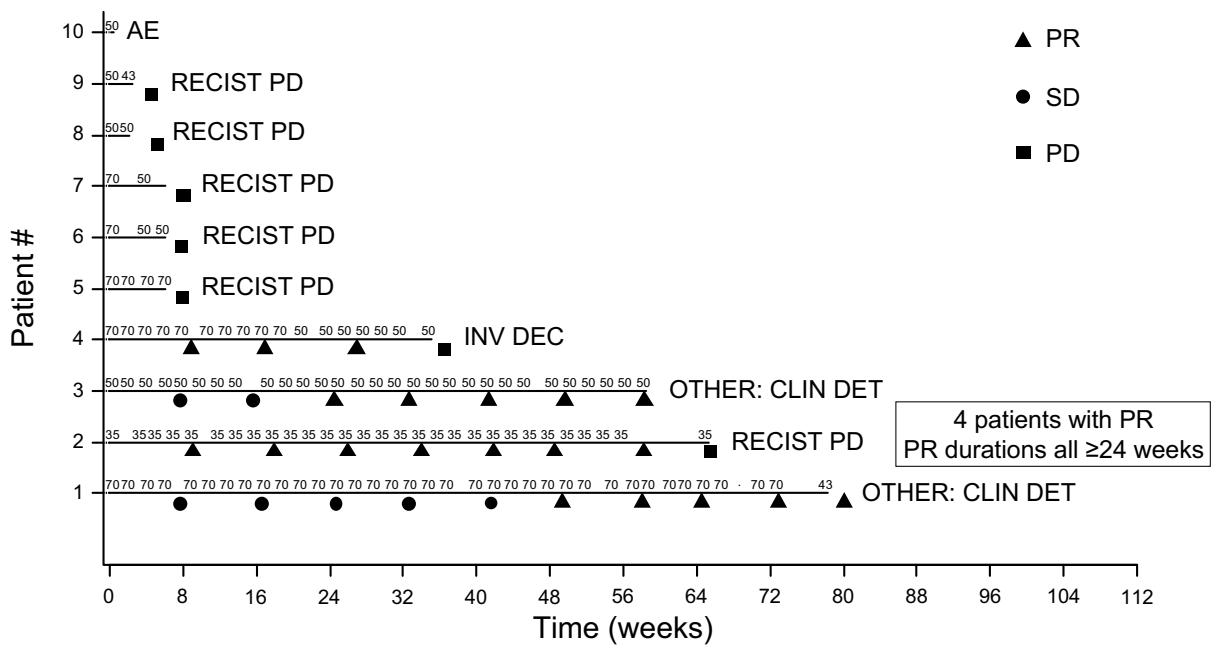

b Cohort 2: patients with TNBC

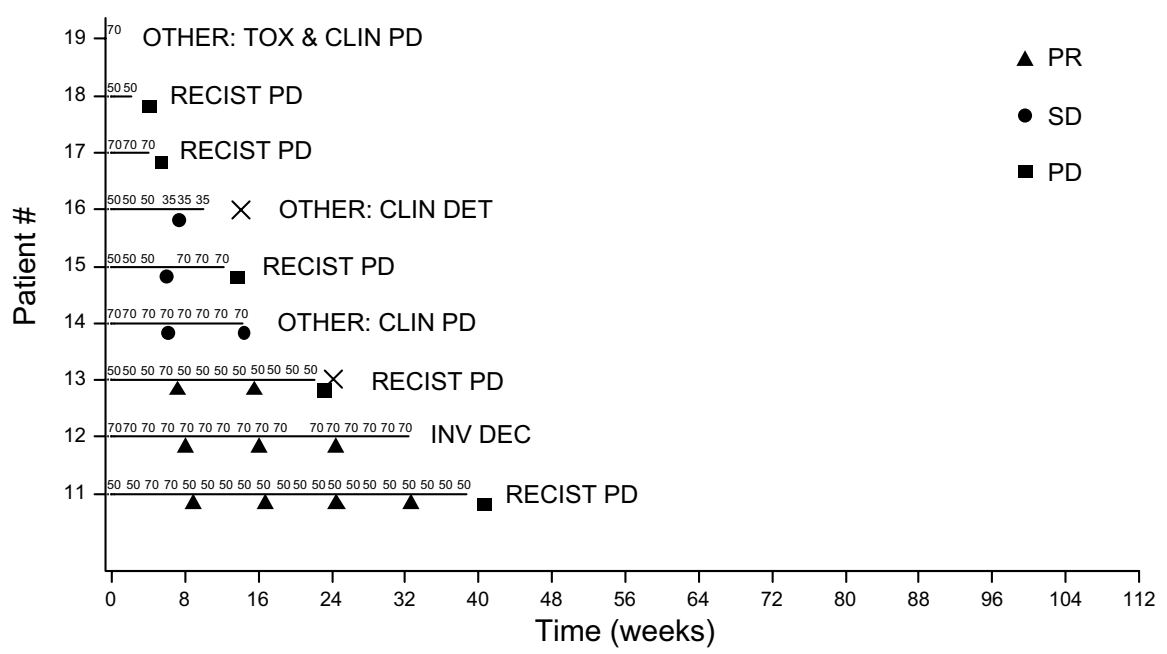

C Cohort 3: patients with $\mathrm{mBC}$ with active $\mathrm{BM}$

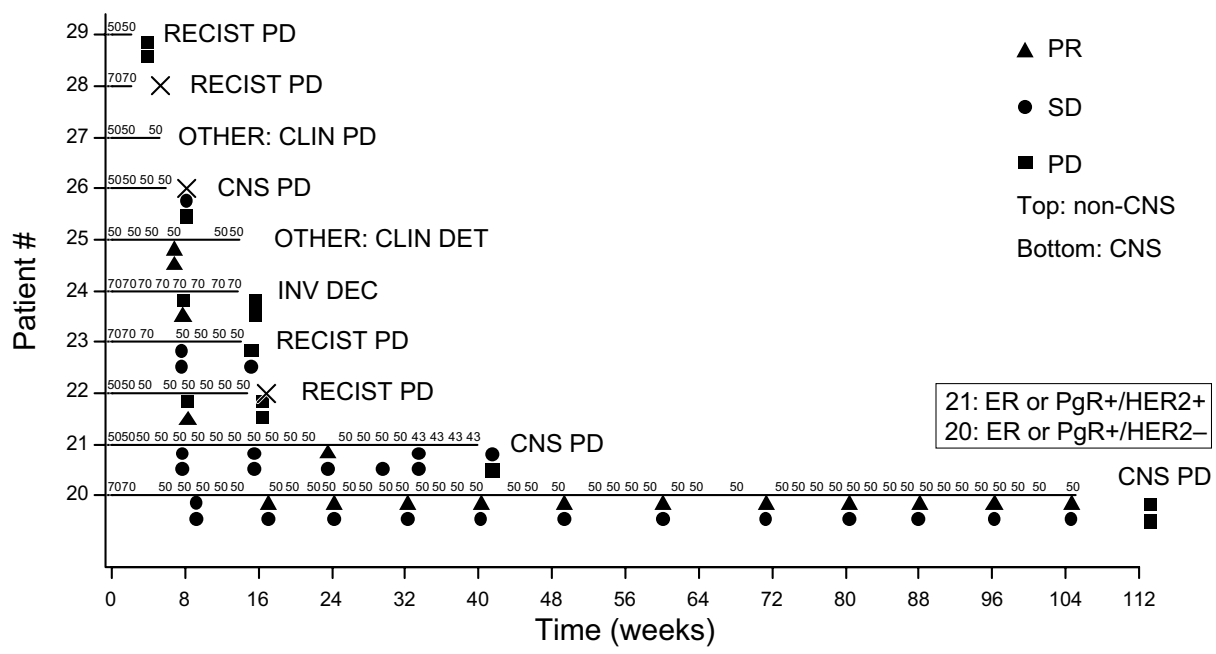


Table 2 Response to treatment (evaluable efficacy population, $N=29$ )

\begin{tabular}{|c|c|c|c|c|c|}
\hline & \multirow{2}{*}{$\begin{array}{l}\text { Cohort } 1 \\
(n=10)\end{array}$} & \multirow{2}{*}{$\begin{array}{l}\text { Cohort } 2^{\mathrm{a}} \\
(n=9)\end{array}$} & \multicolumn{2}{|l|}{ Cohort 3} & \multirow{2}{*}{$\begin{array}{l}\text { Total popula- } \\
\text { tion (non-CNS) } \\
(N=29)\end{array}$} \\
\hline & & & $\begin{array}{l}\text { non-CNS } \\
(n=10)\end{array}$ & $\begin{array}{l}\text { CNS } \\
(n=10)\end{array}$ & \\
\hline \multicolumn{6}{|l|}{ Best overall response, $n(\%)$} \\
\hline Complete response & 0 & 0 & 0 & 0 & 0 \\
\hline Partial response & $4(40.0)$ & $3(33.3)$ & $3(30.0)$ & $3(30.0)$ & $10(34.5)$ \\
\hline Stable disease & 0 & $3(33.3)$ & $2(20.0)$ & $3(30.0)$ & $5(17.2)$ \\
\hline Progressive disease & $5(50.0)$ & $2(22.2)$ & $3(30.0)$ & $2(20.0)$ & $10(34.5)$ \\
\hline Not evaluable & $1(10.0)$ & $1(11.1)$ & $2(20.0)$ & $2(20.0)$ & $4(13.8)$ \\
\hline \multicolumn{6}{|l|}{ Objective response rate } \\
\hline Patients with a complete or partial response, $n(\%)$ & $4(40.0)$ & $3(33.3)$ & $3(30.0)$ & $3(30.0)$ & $10(34.5)$ \\
\hline $95 \% \mathrm{CI}$ & $12.16-73.76$ & $7.49-70.07$ & $6.67-65.25$ & $6.67-65.25$ & $17.94-54.33$ \\
\hline \multicolumn{6}{|l|}{ Clinical benefit rate } \\
\hline $\begin{array}{l}\text { Patients with a complete or partial response, or } \\
\text { stable disease that lasted at least } 24 \text { weeks, } n(\%)\end{array}$ & $4(40.0)$ & $3(33.3)$ & $3(30.0)$ & $5(50.0)$ & $10(34.5)$ \\
\hline $95 \% \mathrm{CI}$ & $12.16-73.76$ & $7.49-70.07$ & $6.67-65.25$ & $18.71-81.29$ & $17.94-54.33$ \\
\hline \multicolumn{6}{|l|}{ Duration of objective response } \\
\hline Number of months, median (range) & $7.46(6.4-13.0)$ & $5.62(3.7-7.4)$ & $4.14(0.0-22.2)$ & $1.84(0.0-1.9)$ & $6.74(0.0-22.2)$ \\
\hline \multicolumn{6}{|l|}{ Progression-free survival } \\
\hline Number of months, median (range) & $1.9(1.1-15.1)$ & $4.3(1.0-9.4)$ & $3.2(0.9-26.1)$ & $3.6(0.9-9.6)$ & $3.2(1.8-8.4)$ \\
\hline
\end{tabular}

CNS tumor response was evaluated according to modified RECIST

Percentages are subject to rounding

CI confidence interval, CNS central nervous system, RECIST Response Evaluation Criteria in Solid Tumors

${ }^{a}$ One patient was enrolled but not treated with liposomal irinotecan and is not included in any safety or efficacy assessments. Non-CNS tumor response was evaluated according to RECIST v1.1

\section{Duration of response}

In cohort 1 (ER+ and/or PgR+/HER2-), PR was reported in four patients; it lasted at least 24 weeks in three of the patients and more than 48 weeks in the fourth patient (Fig. 2a). In cohort 2 (TNBC), PR was reported in three patients; it lasted approximately 24 weeks in two of the patients and 40 weeks in the third patient (Fig. 2b). In cohort 3 (mBCBM), non-CNS PR was reported in three patients; CNS PR was reported in three patients (all of whom had TNBC) at week 8, but not at a subsequent assessment (Fig. 2c). One patient (TNBC) in cohort 3 had a non-CNS and a CNS PR at week 8, and another patient (ER+ and/or PgR+/HER2-) had a non-CNS PR from week 16 to 114 and a best CNS response of SD over the same time period).

Across all cohorts for non-CNS disease, median (range) DOR and PFS were $6.74(0.0-22.2)$ months and 3.2 (1.8-8.4) months, respectively (Table 2). For CNS disease in cohort $3(\mathrm{mBCBM})$, median (range) DOR and PFS were $1.84(0.0-1.9)$ months and $3.6(0.9-9.6)$ months, respectively (Table 2).

\section{Tumor lesion size}

There were 23 patients across all cohorts with measurable non-CNS disease with evaluable follow-up; seven patients in cohort 3 had measurable CNS disease and evaluable followup (Fig. 3). A reduction in tumor lesion size was observed in the majority of patients for both non-CNS disease (14 of 23 patients, $60.9 \%$; Fig. 3a) and CNS disease (six of seven patients, $85.7 \%$; Fig. $3 \mathrm{~b}$ ). In cohort 2 (TNBC) and for the non-CNS disease in cohort $3(\mathrm{mBCBM})$, a reduction was observed in more than half of the evaluable patients. Compared with baseline measures, reductions varied from 5 to $90 \%$ for non-CNS lesions and from 7 to $55 \%$ for CNS lesions.

\section{Safety}

Median duration of exposure to liposomal irinotecan across all cohorts was 12.3 (0.1-105.3) weeks (Table 3). A dose reduction was recorded in six patients who initiated liposomal irinotecan at $70 \mathrm{mg} / \mathrm{m}^{2}$ free base, and in three patients who initiated at $50 \mathrm{mg} / \mathrm{m}^{2}$ free base (Fig. 2). A dose increase 
Fig. 3 Percentage reduction in tumor lesion size in patients with (a) non-CNS disease and (b) CNS disease ${ }^{\mathrm{a}}$. ${ }^{\mathrm{a}}$ Only patients who had an evaluable post-baseline tumor assessment for designated target lesions are included in the waterfall plots. Horizontal dashed lines represent the range of stable disease (lower line, $<30 \%$ reduction in tumor size; upper line, $<20 \%$ increase in tumor size), as per RECIST v1.1 criteria. Patient numbers on the $\mathrm{x}$ axis relate to patient numbers on Fig. 2. BM brain metastases, $C N S$ central nervous system, $E R$ estrogen receptor, HER2 human epidermal growth factor receptor 2 , $m B C$ metastatic breast cancer, $P g R$ progesterone receptor, RECIST Response Evaluation Criteria in Solid Tumors, TNBC triple-negative breast cancer a Non-CNS disease

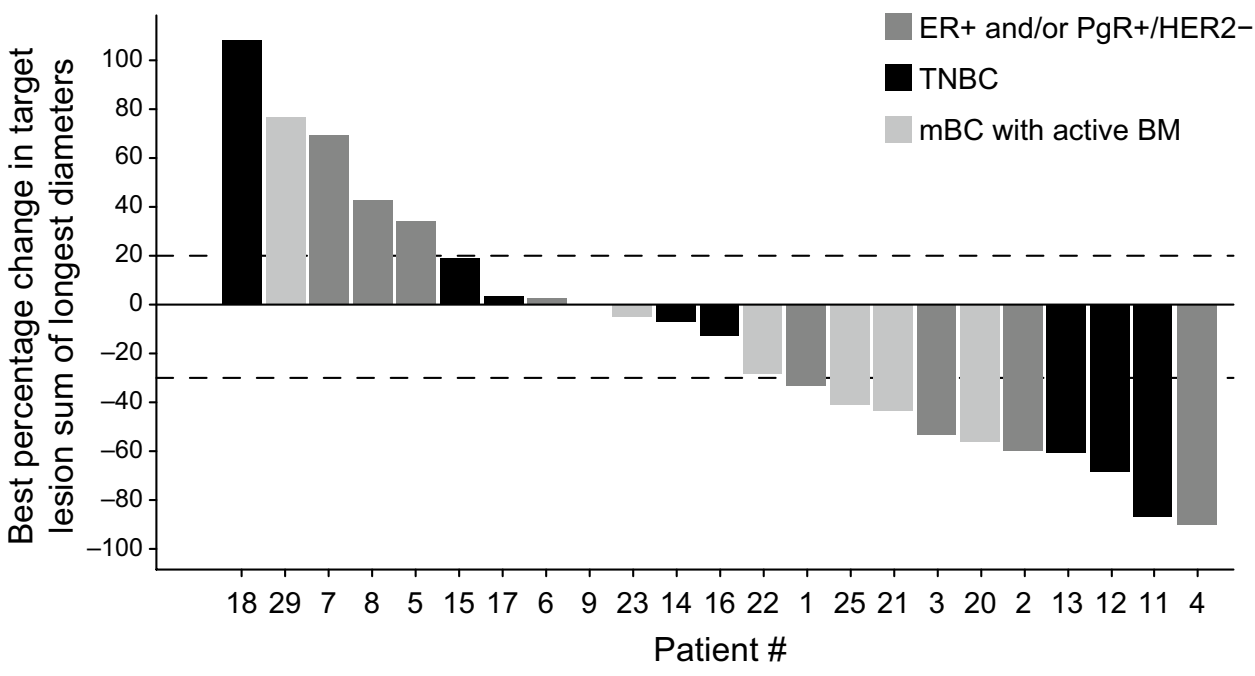

b CNS disease

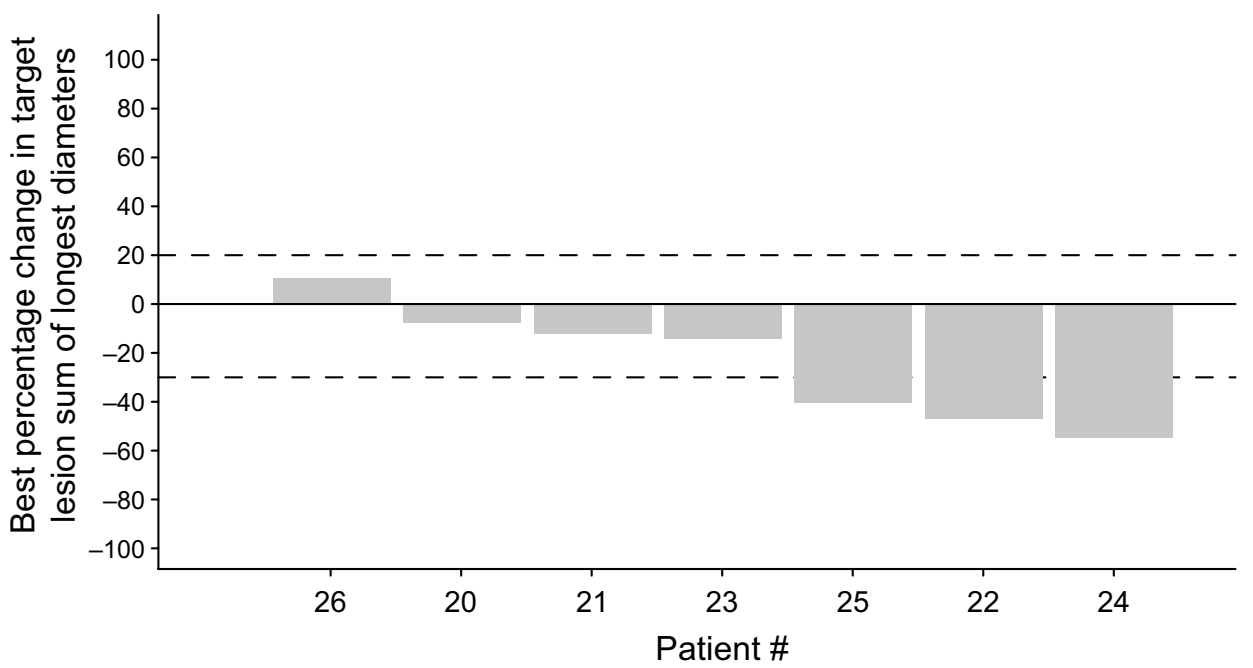

was recorded in a further three patients who initiated liposomal irinotecan at $50 \mathrm{mg} / \mathrm{m}^{2}$ free base; of these, two patients had subsequent dose reductions (Fig. 2). All patients experienced TEAEs, with 28 patients $(96.6 \%)$ experiencing TEAEs that were considered treatment related (Table 3). The most frequently reported TEAEs (reported in $\geq 25 \%$ of all patients) of any grade were diarrhea (89.7\%), fatigue $(62.1 \%)$, nausea $(55.2 \%)$, vomiting $(41.4 \%)$, hypokalemia $(37.9 \%)$, and decreased appetite $(31.0 \%)$. Serious TEAEs were reported in 17 patients (58.6\%) overall and were considered treatment related in six patients $(20.7 \%)$. Serious TEAEs reported in at least $10 \%$ of all patients were diarrhea $(17.2 \%)$, nausea $(10.3 \%)$, and asthenia (10.3\%). In total, 21 patients $(72.4 \%)$ experienced a TEAE with an NCI CTCAE grade of at least 3, with 12 patients (41.4\%) experiencing a grade 3 or higher TEAE that was considered treatment related. TEAEs with an NCI CTCAE grade of at least 3 reported in at least $10 \%$ of all patients were diarrhea
(27.6\%), nausea (17.2\%), fatigue (13.8\%), asthenia (10.3\%), and hypokalemia (10.3\%); all grade 3. No grade 5 TEAEs were reported; no TEAEs resulted in death. One patient (3.4\%) discontinued liposomal irinotecan monotherapy as a result of TEAEs (diarrhea, nausea, and vomiting) that were considered treatment related.

Based on laboratory abnormalities with an NCI CTCAE grade of 3 or 4 , four patients had increased bilirubin, three had hypoglycemia, three had hypokalemia, three had hypophosphatemia, two had low hemoglobin, one had increased aspartate aminotransferase, one had leucopenia, and one had neutropenia (recorded as the MedDRA preferred term, neutrophil count decreased). Based on NCI CTCAE reports of grade 2 neutrophil count decreased, four additional patients had neutropenia, and all five reports of neutropenia were considered treatment related. Two further patients (6.9\%) had an actual NCI CTCAE report of grade 2 neutropenia, one of which was considered treatment related. 
Table 3 Patient safety analysis (liposomal irinotecan safety population, $N=29$ )

\begin{tabular}{|c|c|c|c|c|}
\hline & $\begin{array}{l}\text { Cohort } 1 \\
(n=10)\end{array}$ & $\begin{array}{l}\text { Cohort } 2^{\mathrm{a}} \\
(n=9)\end{array}$ & $\begin{array}{l}\text { Cohort } 3 \\
(n=10)\end{array}$ & $\begin{array}{l}\text { Total population } \\
(N=29)\end{array}$ \\
\hline \multicolumn{5}{|l|}{ Exposure, median (range) } \\
\hline Treatment duration, weeks & $6.1(0.1-78.4)$ & $12.3(0.1-38.9)$ & $13.9(2.1-105.3)$ & $12.3(0.1-105.3)$ \\
\hline \multicolumn{5}{|l|}{ AEs, $n(\%)$} \\
\hline Any TEAE & $10(100.0)$ & $9(100.0)$ & $10(100.0)$ & $29(100.0)$ \\
\hline TEAEs related to liposomal irinotecan & $10(100.0)$ & $8(88.9)$ & $10(100.0)$ & $28(96.6)$ \\
\hline Serious TEAEs & $6(60.0)$ & $4(44.4)$ & $7(70.0)$ & $17(58.6)$ \\
\hline Serious TEAEs related to liposomal irinotecan & $4(40.0)$ & $1(11.1)$ & $1(10.0)$ & $6(20.7)$ \\
\hline TEAEs with NCI CTCAE grade $\geq 3$ & $8(80.0)$ & $6(66.7)$ & $7(70.0)$ & $21(72.4)$ \\
\hline TEAEs with NCI CTCAE grade $\geq 3$ related to liposomal irinotecan & $6(60.0)$ & $3(33.3)$ & $3(30.0)$ & $12(41.4)$ \\
\hline TEAEs leading to liposomal irinotecan discontinuation & $1(10.0)$ & 0 & 0 & $1(3.4)$ \\
\hline $\begin{array}{l}\text { TEAEs leading to liposomal irinotecan discontinuation related to } \\
\text { liposomal irinotecan }\end{array}$ & $1(10.0)$ & 0 & 0 & $1(3.4)$ \\
\hline TEAEs leading to death & 0 & 0 & 0 & 0 \\
\hline TEAEs leading to death related to liposomal irinotecan & 0 & 0 & 0 & 0 \\
\hline TEAEs leading to dose adjustment & $7(70.0)$ & $7(77.8)$ & $6(60.0)$ & $20(69.0)$ \\
\hline TEAEs leading to dose adjustment related to liposomal irinotecan & $7(70.0)$ & $4(44.4)$ & $4(40.0)$ & $15(51.7)$ \\
\hline \multicolumn{5}{|l|}{ Commonly reported TEAEs ( $>25 \%$ in any cohort) } \\
\hline Diarrhea & $10(100.0)$ & $9(100.0)$ & $7(70.0)$ & $26(89.7)$ \\
\hline Fatigue & $6(60.0)$ & $5(55.6)$ & $7(70.0)$ & $18(62.1)$ \\
\hline Nausea & $8(80.0)$ & $5(55.6)$ & $3(30.0)$ & $16(55.2)$ \\
\hline Vomiting & $6(60.0)$ & $3(33.3)$ & $3(30.0)$ & $12(41.4)$ \\
\hline Hypokalemia & $4(40.0)$ & $3(33.3)$ & $4(40.0)$ & $11(37.9)$ \\
\hline Decreased appetite & $5(50.0)$ & $2(22.2)$ & $2(20.0)$ & $9(31.0)$ \\
\hline Back pain & $4(40.0)$ & $1(11.1)$ & $2(20.0)$ & $7(24.1)$ \\
\hline Alanine aminotransferase increased & $3(30.0)$ & 0 & $4(40.0)$ & $7(24.1)$ \\
\hline Anemia & $3(30.0)$ & $2(22.2)$ & $2(20.0)$ & $7(24.1)$ \\
\hline Abdominal pain & $3(30.0)$ & $3(33.3)$ & $1(10.0)$ & $7(24.1)$ \\
\hline Headache & $3(30.0)$ & $1(11.1)$ & $2(20.0)$ & $6(20.7)$ \\
\hline Cough & $1(10.0)$ & $2(22.2)$ & $3(30.0)$ & $6(20.7)$ \\
\hline Alopecia & $4(40.0)$ & $2(22.2)$ & 0 & $6(20.7)$ \\
\hline Hypocalcemia & $3(30.0)$ & $2(22.2)$ & $1(10.0)$ & $6(20.7)$ \\
\hline Asthenia & $1(10.0)$ & $1(11.1)$ & $3(30.0)$ & $5(17.2)$ \\
\hline Constipation & $3(30.0)$ & 0 & $2(20.0)$ & $5(17.2)$ \\
\hline Dyspnea & $1(10.0)$ & 0 & $4(40.0)$ & $5(17.2)$ \\
\hline
\end{tabular}

$A E$ adverse event, NCI CTCAE National Cancer Institute Common Terminology Criteria for Adverse Events, TEAE treatment-emergent adverse event

${ }^{a}$ One patient was enrolled but not treated with liposomal irinotecan and is not included in any safety or efficacy assessments

\section{Metastatic tumor receptor status-exploratory, post hoc analyses}

Among patients who received liposomal irinotecan and had evaluable on-study biopsies, metastatic tumor receptor status was discordant with cohort assignment for four of ten patients in cohort 1 (ER- and PR-, one patient [\#8]; HER2+, three patients [\#3, \#5, \#9]) and two of seven patients in cohort 2 (HER2+, one patient [\#16]; ER+ and HER2+, one patient [\#12]) (Supplementary Table S3).

\section{Discussion}

This study is the first to evaluate the efficacy and safety of liposomal irinotecan specifically in heavily pretreated adult patients with $\mathrm{mBC}$, including those with active BM. Findings from the expansion phase of this open-label, phase I study demonstrate the antitumor activity of liposomal irinotecan monotherapy. Liposomal irinotecan was relatively well tolerated, with only one patient discontinuing because of TEAEs (diarrhea, nausea, and vomiting). 
Despite recent improvements in survival rates, $\mathrm{mBC}$ remains an incurable disease, and new treatment options are needed, particularly because response rates in late lines of treatment and in patients with BM remain low. Typically, clinical trials of new agents exclude patients with active or untreated BM, and therefore CNS disease remains particularly challenging to treat. However, based on positive findings from the HER2CLIMB trial in patients with HER2+ mBC, which did include patients with BM [16], the HER2 inhibitor tucatinib, in combination with capecitabine and trastuzumab, recently received FDA-approval for the treatment of patients with advanced unresectable or metastatic HER 2+ breast cancer, including patients with BM [4]. Neratinib and lapatinib are also small-molecule inhibitors of HER2 [17, 18], and have shown modest activity as single agents or in combination with capecitabine for treating HER2+ mBCBM. The present study evaluated heavily pretreated patients with $\mathrm{mBC}$, including those with active $\mathrm{BM}$; some patients have been living with $\mathrm{mBC}$ for more than 5 years. The study population is therefore representative of patients with high unmet need and for whom additional standard treatment options would not be expected to provide robust responses or durable benefit.

Endocrine, targeted, and cytotoxic systemic treatments used as monotherapy in pretreated patients with $\mathrm{mBC}$ have been reportedly associated with ORRs ranging from 14 to $32 \%$; combination treatments are associated with improved ORRs [19]. Two small, single-arm clinical trials have specifically assessed the use of non-liposomal irinotecan monotherapy in patients with $\mathrm{mBC}$, with reported ORRs of $5.6 \%$ and $23 \%$ [20, 21]. Studies of non-liposomal irinotecan in combination with a chemotherapeutic agent in patients with $\mathrm{mBC}$ have reported ORRs ranging from 11 to $58.3 \%$ [22-29]. In addition, in a small-scale pilot study that assessed the use of multi-omic profiling of target tumors to guide treatment selection in patients with $\mathrm{mBC}$, the most frequently selected treatment was irinotecan based on identified topoisomerase I expression in 12 of 25 evaluated patients ( 7 received irinotecan combination therapy; 5 received irinotecan monotherapy) [30]. Of these 25 patients, $14(56 \%)$ exhibited clinical benefit (defined as growth modulation index $\geq 1.3$ ) [30]. One phase II study that assessed etirinotecan pegol, a long-acting formulation of irinotecan, reported an ORR of $29 \%$ [31]; however, the drug failed to demonstrate superiority to the physician's choice (singledrug treatment) for overall survival in the randomized phase III BEACON trial [32].

In the present study, the ORR observed with liposomal irinotecan (34.5\%) was numerically higher than that historically reported with non-liposomal irinotecan monotherapy $[20,21]$. This may be due to the prolonged plasma circulation and EPR effect observed with near-nanoscale liposomal irinotecan, both of which allow for improved tumor drug delivery. Nanoparticle deposition within patients' intracranial tumor lesions has previously been reported for ferumoxytol as assessed by MRI [15] and liposomes with comparable dimensions and lipid compositions to liposomal irinotecan as assessed by positron emission tomography [33]. The ability of liposomal irinotecan to penetrate the blood-tumor-barrier, in part owing to the small diameter of the liposomes $(110 \mathrm{~nm})$, and accumulate in CNS lesions has been demonstrated in non-clinical models of intracranial metastasis in breast cancer [13] and orthotopic glioblastoma models [8, 34]. Liposomes crossed the blood-tumor-barrier and accumulated in brain metastases, but not in normal brain tissue. Extended and preferential accumulation of irinotecan and the active metabolite, $\mathrm{SN}-38$, were observed in these models compared to treatment with non-liposomal irinotecan $[8,13]$.

In the pilot phase of this study, total SN-38 levels and the ratio of total SN-38:total irinotecan were reportedly sixfold and eightfold higher in tumors than in plasma [12]. In the phase III NAPOLI-1 study in patients with mPDAC, average concentration and duration above threshold concentration for unencapsulated $\mathrm{SN}-38$ in a population pharmacokinetics model were positively correlated with overall response rate, PFS and overall survival in patients receiving liposomal irinotecan with 5-fluorouracil/leucovorin [12]. Thus, the favorable pharmacokinetic characteristics of liposomal irinotecan likely contributed to the efficacy observed in the present study. The ORR with liposomal irinotecan was $30 \%$ for CNS disease in cohort $3(\mathrm{mBCBM})$, and $50 \%$ of patients demonstrated clinical benefit. Two previous openlabel, phase I studies that assessed liposomal irinotecan in patients with advanced solid tumors refractory to standard systemic chemotherapy included a small subset of patients with $\mathrm{mBC}[35,36]$. The observed BOR with liposomal irinotecan was PR in one of four patients with $\mathrm{mBC}$ in one study [35], and SD in one of two patients with $\mathrm{mBC}$ in the second study [36]. The present study provides additional evidence of the antitumor activity of liposomal irinotecan in a heavily pretreated population with $\mathrm{mBC}$, including $\mathrm{BM}$, supporting further investigation.

ORRs observed in this study were similar across all cohorts (ER+ and/or PgR+/HER2-, TNBC or mBCBM), demonstrating liposomal irinotecan activity in all subtypes of $\mathrm{mBC}$. Notably, of the five patients in cohort 3 who had a PR (non-CNS PR, two patients; CNS PR, two patients; both non-CNS and CNS PR, one patient), three had TNBC (a total of four patients had TNBC in cohort 3), one patient had ER+ or PgR+/HER2 + mBC, and one patient had ER+ or PgR+/HER2 - mBC. In these two patients with hormonereceptor-positive $\mathrm{mBC}$ with a $\mathrm{PR}$, durable responses were noted for both CNS and non-CNS disease; lasting 40 weeks in the patient with HER2+ mBC, and 104 weeks in the patient with HER2- mBC. These findings warrant further 
investigation of liposomal irinotecan in patients with $\mathrm{mBC}$ and $\mathrm{BM}$, including those with TNBC for whom existing treatment options are extremely limited.

Our exploratory post hoc analyses of metastatic tumor receptor status were consistent with previous reports of the potential for discordance and receptor conversion between primary and metastatic tumors [37], highlighting the need to consider inter- and intra-tumor heterogeneity when selecting treatments [38].

The observed safety profile of liposomal irinotecan was consistent with that reported in earlier studies of non-liposo$\mathrm{mal}$ and liposomal irinotecan, with gastrointestinal TEAEs, including diarrhea, nausea, and vomiting, being among the most commonly reported grade 3 or 4 TEAEs [20, 21, 24, $25,28,35,36,39,40]$; no new or unexpected TEAEs were reported. Perhaps the most noticeable difference between previous studies and the present findings is the absence of grade 3 or 4 neutropenia; however, it should be noted that neutropenia was observed in seven patients (NCI CTCAE records of grade 2 neutropenia in three patients, grade 2 neutrophil count decreased in three patients, and grade 3 neutrophil count decreased in one patient). This finding supports the suggestion that liposomal irinotecan monotherapy is associated with better tolerability than liposomal irinotecan combination therapy [41]. In the phase III NAPOLI-1 study, neutropenia was reported in $23.08 \%$ of patients receiving liposomal irinotecan $70 \mathrm{mg} / \mathrm{m}^{2}$ free base every 2 weeks in combination with 5-fluorouracil/leucovorin [41]. The relatively low frequency of neutropenia observed in the current study may, in part, be due to the dose of liposomal irinotecan and/or the increased localization of liposomal irinotecan within target lesions (rather than in plasma) via the EPR effect $[11,12]$. Improved tumor drug delivery via innovative therapeutic platforms, such as nanotherapeutics or antibody drug conjugates (ADCs), are major areas of research for increasing the efficacy of cytotoxic agents while minimizing toxicity. Sacituzumab govitecan-hziy is an ADC comprised of a Trop-2 monoclonal antibody linked to a SN-38 payload, that was recently approved for patients with metastatic TNBC who have received at least two prior lines of therapy for metastatic disease $[42,43]$. This agent demonstrated an ORR of $33.3 \%$ in a population with a median of three prior lines of treatment, similar to the patient population in the present study [42]. However, this study excluded patients with active, symptomatic, or untreated BM. Thus, the CNS activity of sacituzumab govitecan-hziy is unknown at present. Future research will hopefully continue to elucidate optimal drug delivery mechanisms to maximize the therapeutic potential of irinotecan in $\mathrm{mBC}$, particularly in patients with untreated BCBM.

The main strength of the present study is that liposomal irinotecan was assessed specifically in patients with $\mathrm{mBC}$, including those with active BM. Our findings provide a springboard for further investigation of liposomal irinotecan in this population, in whom alternative therapies are still needed. Study limitations include a small sample size, the open-label study design, and the lack of a comparator group; however, this study showed encouraging antitumor activity in this heavily pretreated population who had experienced disease progression despite multiple lines of chemotherapy.

\section{Conclusions}

Among heavily pretreated patients with $\mathrm{mBC}$ with or without BM, liposomal irinotecan monotherapy every 2 weeks had a safety profile consistent with that previously reported for liposomal irinotecan in patients with solid tumors and was associated with an ORR of at least $30 \%$. In future trials, proactive management of gastrointestinal toxicities, such as diarrhea, could improve the risk-benefit profile of liposomal irinotecan. These results suggest that further clinical assessment of liposomal irinotecan is warranted in $\mathrm{mBC}$ and active BM.

Acknowledgements The authors thank all patients involved in the study, as well as their caregivers, care teams, investigators, and research staff in participating institutions. Medical writing support The authors thank David Gothard, PhD, and Tamzin Gristwood, PhD, of Oxford PharmaGenesis, Oxford, UK, for providing medical writing support, which was sponsored by Ipsen, in accordance with Good Publication Practice (GPP3) guidelines.

Author contributions All authors have contributed to study conception/design, acquisition/analysis/interpretation of the data, drafting the publication or revising it critically for scientific accuracy and important intellectual content, and final approval of the publication.

Funding This study was sponsored by Ipsen.

Data availability If patient data can be anonymized, Ipsen will share all individual patient data that underlie the results reported in this article with qualified researchers who provide a valid research question. Study documents, such as the clinical study report, are not always available. Proposals should be submitted to DataSharing@Ipsen.com and will be assessed by a scientific review board. Data are available beginning 6 months, and ending 5 years, after publication; after this time, only raw data may be available.

\section{Compliance with ethical standards}

Conflict of interest Jasgit C. Sachdev has received research funding from Celgene, Genentech, and Pfizer; compensation for the role of adviser from Celgene, Ipsen, Novartis, Pfizer, Puma Biotechnology, TapImmune, Tempus, and TTC Oncology; and honorarium from Celgene, Ipsen, Novartis, Pfizer, Puma Biotechnology, and Tempus. Hyo Sook Han has received research funding from AbbVie, Bristol Myers Squibb, the Department of Defense, Horizon Therapeutics, Ipsen, Karyopharm Therapeutics, Novartis, Pfizer, Prescient, Seattle Genetics, TapImmune, and Tesaro; and compensation for a speaker's bureau from Eli Lilly. Cynthia Ma has received research funding from Pfizer, Puma Biotechnology, and Tempus; compensations for a consulting 
role for Agendia, AstraZeneca, Eli Lilly, Novartis, OncoSignal, Pfizer, Seattle Genetics, and Tempus. Fiona Maxwell, Tiffany Wang, Bruce Belanger, Bin Zhang, Yan Moore, and Arunthathi Thiagalingam are employees of Ipsen and hold stock or stock options. Carey Anders has received research funding from Eli Lilly, G1-Therapeutics, Merck, Nektar Technology, Puma Biotechnology, Seattle Genetics, and Tesaro; compensation for a consultant role from Eisai, Genentech, Ipsen, Puma Biotechnology, and Seattle Genetics; and royalties from Jones \& Bartlett Learning and UpToDate. Pamela Munster and Donald W. Northfelt have nothing to disclose.

Open Access This article is licensed under a Creative Commons Attribution 4.0 International License, which permits use, sharing, adaptation, distribution and reproduction in any medium or format, as long as you give appropriate credit to the original author(s) and the source, provide a link to the Creative Commons licence, and indicate if changes were made. The images or other third party material in this article are included in the article's Creative Commons licence, unless indicated otherwise in a credit line to the material. If material is not included in the article's Creative Commons licence and your intended use is not permitted by statutory regulation or exceeds the permitted use, you will need to obtain permission directly from the copyright holder. To view a copy of this licence, visit http://creativecommons.org/licenses/by/4.0/.

\section{References}

1. Cancer.Net (2020) Breast cancer-metastatic: statistics. https:// www.cancer.net/cancer-types/breast-cancer-metastatic/statistics. Accessed 7 Sept 2020

2. Rostami R, Mittal S, Rostami P, Tavassoli F, Jabbari B (2016) Brain metastasis in breast cancer: a comprehensive literature review. J Neurooncol 127(3):407-414. https://doi.org/10.1007/ s11060-016-2075-3

3. Cardoso F, Bedard PL, Winer EP, Pagani O, Senkus-Konefka E, Fallowfield LJ, Kyriakides S, Costa A, Cufer T, Albain KS (2009) International guidelines for management of metastatic breast cancer: combination vs sequential single-agent chemotherapy. J Natl Cancer Inst 101(17):1174-1181. https://doi.org/10.1093/jnci/ djp235

4. Seattle Genetics Inc. (2020) Prescribing information, TUKYSA $^{\mathrm{TM}}$ (tucatinib) tablets, for oral use. US Food and Drug Administration. https://www.accessdata.fda.gov/drugsatfda_docs/ label/2020/213411s000lbl.pdf. Accessed 9 Sept 2020

5. Ipsen Biopharmaceuticals, Inc. (2017) Prescribing Information, ONIVYDE® (irinotecan liposome injection). US Food and Drug Administration. https://www.ipsen.com/websites/Ipsen_Online/ wp-content/uploads/sites/9/2019/01/21083350/ONIVYDE_USPI. pdf. Accessed 12 Aug 2019

6. Turner CD, Gururangan S, Eastwood J, Bottom K, Watral M, Beason R, McLendon RE, Friedman AH, Tourt-Uhlig S, Miller LL, Friedman HS (2002) Phase II study of irinotecan (CPT-11) in children with high-risk malignant brain tumors: the Duke experience. Neuro Oncol 4(2):102-108. https://doi.org/10.1093/neuon c/4.2.109

7. Anders C, Deal AM, Abramson V, Liu MC, Storniolo AM, Carpenter JT, Puhalla S, Nanda R, Melhem-Bertrandt A, Lin NU, Kelly Marcom P, Van Poznak C, Stearns V, Melisko M, Smith JK, Karginova O, Parker J, Berg J, Winer EP, Peterman A, Prat A, Perou CM, Wolff AC, Carey LA (2014) TBCRC 018: phase II study of iniparib in combination with irinotecan to treat progressive triple negative breast cancer brain metastases. Breast
Cancer Res Treat 146(3):557-566. https://doi.org/10.1007/s1054 9-014-3039-y

8. Noble CO, Krauze MT, Drummond DC, Forsayeth J, Hayes ME, Beyer J, Hadaczek P, Berger MS, Kirpotin DB, Bankiewicz KS, Park JW (2014) Pharmacokinetics, tumor accumulation and antitumor activity of nanoliposomal irinotecan following systemic treatment of intracranial tumors. Nanomedicine (Lond) 9(14):2099-2108. https://doi.org/10.2217/nnm.13.201

9. ISO/TS 80004-1 (2015) Nanotechnologies—vocabulary-Part 1: core terms. https://www.iso.org/standard/68058.html. Accessed 13 Oct 2020

10. Bertrand N, Wu J, Xu X, Kamaly N, Farokhzad OC (2014) Cancer nanotechnology: the impact of passive and active targeting in the era of modern cancer biology. Adv Drug Deliv Rev 66:2-25. https ://doi.org/10.1016/j.addr.2013.11.009

11. Golombek SK, May JN, Theek B, Appold L, Drude N, Kiessling F, Lammers T (2018) Tumor targeting via EPR: strategies to enhance patient responses. Adv Drug Deliv Rev 130:17-38. https ://doi.org/10.1016/j.addr.2018.07.007

12. Adiwijaya BS, Kim J, Lang I, Csoszi T, Cubillo A, Chen JS, Wong M, Park JO, Kim JS, Rau KM, Melichar B, Gallego JB, Fitzgerald J, Belanger B, Molnar I, Ma WW (2017) Population pharmacokinetics of liposomal irinotecan in patients with cancer. Clin Pharmacol Ther 102(6):997-1005. https://doi.org/10.1002/cpt.720

13. Mohammad AS, Griffith JI, Adkins CE, Shah N, Sechrest E, Dolan EL, Terrell-Hall TB, Hendriks BS, Lee H, Lockman PR (2018) Liposomal irinotecan accumulates in metastatic lesions, crosses the blood-tumor barrier (BTB), and prolongs survival in an experimental model of brain metastases of triple negative breast cancer. Pharm Res 35(2):31. https://doi.org/10.1007/s11095-017-2278-0

14. Ramanathan RK, Korn RL, Raghunand N, Sachdev JC, Newbold RG, Jameson G, Fetterly GJ, Prey J, Klinz SG, Kim J, Cain J, Hendriks BS, Drummond DC, Bayever E, Fitzgerald JB (2017) Correlation between ferumoxytol uptake in tumor lesions by MRI and response to nanoliposomal irinotecan in patients with advanced solid tumors: a pilot study. Clin Cancer Res 23(14):3638-3648. https://doi.org/10.1158/1078-0432.ccr-16-1990

15. Toth GB, Varallyay CG, Horvath A, Bashir MR, Choyke PL, Daldrup-Link HE, Dosa E, Finn JP, Gahramanov S, Harisinghani M, Macdougall I, Neuwelt A, Vasanawala SS, Ambady P, Barajas R, Cetas JS, Ciporen J, DeLoughery TJ, Doolittle ND, Fu R, Grinstead J, Guimaraes AR, Hamilton BE, Li X, McConnell HL, Muldoon LL, Nesbit G, Netto JP, Petterson D, Rooney WD, Schwartz D, Szidonya L, Neuwelt EA (2017) Current and potential imaging applications of ferumoxytol for magnetic resonance imaging. Kidney Int 92(1):47-66. https://doi.org/10.1016/j. kint.2016.12.037

16. Murthy RK, Loi S, Okines A, Paplomata E, Hamilton E, Hurvitz SA, Lin NU, Borges V, Abramson V, Anders C, Bedard PL, Oliveira M, Jakobsen E, Bachelot T, Shachar SS, Muller V, Braga S, Duhoux FP, Greil R, Cameron D, Carey LA, Curigliano G, Gelmon K, Hortobagyi G, Krop I, Loibl S, Pegram M, Slamon D, Palanca-Wessels MC, Walker L, Feng W, Winer EP (2019) Tucatinib, trastuzumab, and capecitabine for HER2-positive metastatic breast cancer. N Engl J Med. https://doi.org/10.1056/NEJMo a1914609

17. Freedman RA, Gelman RS, Anders CK, Melisko ME, Parsons HA, Cropp AM, Silvestri K, Cotter CM, Componeschi KP, Marte JM, Connolly RM, Moy B, Van Poznak CH, Blackwell KL, Puhalla SL, Jankowitz RC, Smith KL, Ibrahim N, Moynihan TJ, O'Sullivan CC, Nangia J, Niravath P, Tung N, Pohlmann PR, Burns R, Rimawi MF, Krop IE, Wolff AC, Winer EP, Lin NU (2019) TBCRC 022: a phase II trial of neratinib and capecitabine for patients with human epidermal growth factor 
receptor 2-positive breast cancer and brain metastases. J Clin Oncol 37(13):1081-1089. https://doi.org/10.1200/jco.18.01511

18. Petrelli F, Ghidini M, Lonati V, Tomasello G, Borgonovo K, Ghilardi M, Cabiddu M, Barni S (2017) The efficacy of lapatinib and capecitabine in HER-2 positive breast cancer with brain metastases: a systematic review and pooled analysis. Eur J Cancer 84:141-148. https://doi.org/10.1016/j.ejca.2017.07.024

19. Roche H, Vahdat LT (2011) Treatment of metastatic breast cancer: second line and beyond. Ann Oncol 22(5):1000-1010. https://doi. org/10.1093/annonc/mdq429

20. Perez EA, Hillman DW, Mailliard JA, Ingle JN, Ryan JM, Fitch TR, Rowland KM, Kardinal CG, Krook JE, Kugler JW, Dakhil SR (2004) Randomized phase II study of two irinotecan schedules for patients with metastatic breast cancer refractory to an anthracycline, a taxane, or both. J Clin Oncol 22(14):2849-2855. https:// doi.org/10.1200/jco.2004.10.047

21. Hayashi H, Tsurutani J, Satoh T, Masuda N, Okamoto W, Morinaga R, Terashima M, Miyazaki M, Okamoto I, Nishida Y, Tominaga S, Tokunaga Y, Yamaguchi M, Sakamoto J, Nakayama T, Nakagawa K (2013) Phase II study of bi-weekly irinotecan for patients with previously treated HER2-negative metastatic breast cancer: KMBOG0610B. Breast Cancer 20(2):131-136. https:// doi.org/10.1007/s12282-011-0316-Z

22. Moulder S, Valkov N, Neuger A, Choi J, Lee JH, Minton S, Munster P, Gump J, Lacevic M, Lush R, Sullivan D (2008) Phase 2 study of gemcitabine and irinotecan in metastatic breast cancer with correlatives to determine topoisomerase I localization as a predictor of response. Cancer 113(10):2646-2654. https://doi. org/10.1002/cncr.23916

23. Crozier JA, Advani PP, LaPlant B, Hobday T, Jaslowski AJ, Moreno-Aspitia A, Perez EA (2016) N0436 (Alliance): a phase II trial of irinotecan with cetuximab in patients with metastatic breast cancer previously exposed to anthracycline and/or taxanecontaining therapy. Clin Breast Cancer 16(1):23-30. https://doi. org/10.1016/j.clbc.2015.08.002

24. Stathopoulos GP, Tsavdaridis D, Malamos NA, Rigatos SK, Kosmas C, Pergantas N, Stathopoulos JG, Xynotroulas J (2005) Irinotecan combined with docetaxel in pre-treated metastatic breast cancer patients: a phase II study. Cancer Chemother Pharmacol 56(5):487-491. https://doi.org/10.1007/s00280-005-1006-3

25. Otsuka H, Fujii T, Toh U, Iwakuma N, Takahashi R, Mishima M, Takenaka M, Kakuma T, Tanaka M, Shirouzu K (2015) Phase II clinical trial of metronomic chemotherapy with combined irinotecan and tegafur-gimeracil-oteracil potassium in metastatic and recurrent breast cancer. Breast Cancer 22(4):335-342. https://doi. org/10.1007/s12282-013-0483-1

26. Park IH, Im SA, Jung KH, Sohn JH, Park YH, Lee KS, Sim SH, Park KH, Kim JH, Nam BH, Kim HJ, Kim TY, Lee KH, Kim SB, Ahn JH, Lee S, Ro J (2019) Randomized open label phase III trial of irinotecan plus capecitabine versus capecitabine monotherapy in patients with metastatic breast cancer previously treated with anthracycline and taxane: PROCEED trial (KCSG BR 11-01). Cancer Res Treat 51(1):43-52. https://doi.org/10.4143/ crt.2017.562

27. Tan WW, Hillman DW, Salim M, Northfelt DW, Anderson DM, Stella PJ, Niedringhaus R, Bernath AM, Gamini SS, Palmieri F, Perez EA (2010) N0332 phase 2 trial of weekly irinotecan hydrochloride and docetaxel in refractory metastatic breast cancer: a North Central Cancer Treatment Group (NCCTG) trial. Ann Oncol 21(3):493-497. https://doi.org/10.1093/annonc/mdp328

28. Lee KS, Park IH, Nam BH, Ro J (2013) Phase II study of irinotecan plus capecitabine in anthracycline- and taxane- pretreated patients with metastatic breast cancer. Invest New Drugs 31(1):152-159. https://doi.org/10.1007/s10637-012-9824-8

29. Kashiwaba M, Inaba T, Komatsu H, Ishida K, Kawagishi R, Matsui Y, Uesugi N, Sugai T, Wakabayashi G (2014) A phase I study of capecitabine combined with CPT-11 in metastatic breast cancer pretreated with anthracyclines and taxanes. Oncology 86(4):206211. https://doi.org/10.1159/000358596

30. Pierobon M, Robert NJ, Northfelt DW, Jahanzeb M, Wong S, Hodge KA, Aldrich J, Craig DW, Liotta LA, Wulfkuhle JD, Gallagher RI, Arguello D, Conrad A, Kemkes AC, Loesch DM, Vocila L, Dunetz B, Carpten JD, Petricoin EF, Anthony SP (2018) Multi-omic profiling of metastatic lesions to guide treatment selection: the side out 2 trial experience. J Clin Oncol 36:1077. https://doi.org/10.1200/JCO.2018.36.15_suppl.1077

31. Awada A, Garcia AA, Chan S, Jerusalem GH, Coleman RE, Huizing MT, Mehdi A, O'Reilly SM, Hamm JT, Barrett-Lee PJ, Cocquyt V, Sideras K, Young DE, Zhao C, Chia YL, Hoch U, Hannah AL, Perez EA (2013) Two schedules of etirinotecan pegol (NKTR-102) in patients with previously treated metastatic breast cancer: a randomised phase 2 study. Lancet Oncol 14(12):12161225. https://doi.org/10.1016/s1470-2045(13)70429-7

32. Perez EA, Awada A, O'Shaughnessy J, Rugo HS, Twelves C, Im SA, Gomez-Pardo P, Schwartzberg LS, Dieras V, Yardley DA, Potter DA, Mailliez A, Moreno-Aspitia A, Ahn JS, Zhao C, Hoch U, Tagliaferri M, Hannah AL, Cortes J (2015) Etirinotecan pegol (NKTR-102) versus treatment of physician's choice in women with advanced breast cancer previously treated with an anthracycline, a taxane, and capecitabine (BEACON): a randomised, openlabel, multicentre, phase 3 trial. Lancet Oncol 16(15):1556-1568. https://doi.org/10.1016/s1470-2045(15)00332-0

33. Lee H, Shields AF, Siegel BA, Miller KD, Krop I, Ma CX, LoRusso PM, Munster PN, Campbell K, Gaddy DF, Leonard SC, Geretti E, Blocker SJ, Kirpotin DB, Moyo V, Wickham TJ, Hendriks BS (2017) (64)Cu-MM-302 positron emission tomography quantifies variability of enhanced permeability and retention of nanoparticles in relation to treatment response in patients with metastatic breast cancer. Clin Cancer Res 23(15):4190-4202. https://doi.org/10.1158/1078-0432.Ccr-16-3193

34. Chen PY, Ozawa T, Drummond DC, Kalra A, Fitzgerald JB, Kirpotin DB, Wei KC, Butowski N, Prados MD, Berger MS, Forsayeth JR, Bankiewicz K, James CD (2013) Comparing routes of delivery for nanoliposomal irinotecan shows superior antitumor activity of local administration in treating intracranial glioblastoma xenografts. Neuro Oncol 15(2):189-197. https:// doi.org/10.1093/neuonc/nos305

35. Chiang NJ, Chao TY, Hsieh RK, Wang CH, Wang YW, Yeh CG, Chen LT (2016) A phase I dose-escalation study of PEP02 (irinotecan liposome injection) in combination with 5-fluorouracil and leucovorin in advanced solid tumors. BMC Cancer 16(1):907. https://doi.org/10.1186/s12885-016-2933-6

36. Chang TC, Shiah HS, Yang CH, Yeh KH, Cheng AL, Shen BN, Wang YW, Yeh CG, Chiang NJ, Chang JY, Chen LT (2015) Phase I study of nanoliposomal irinotecan (PEP02) in advanced solid tumor patients. Cancer Chemother Pharmacol 75(3):579-586. https://doi.org/10.1007/s00280-014-2671-x

37. Meng X, Song S, Jiang ZF, Sun B, Wang T, Zhang S, Wu S (2016) Receptor conversion in metastatic breast cancer: a prognosticator of survival. Oncotarget 7(44):71887-71903. https://doi. org/10.18632/oncotarget.12114

38. Joseph C, Papadaki A, Althobiti M, Alsaleem M, Aleskandarany MA, Rakha EA (2018) Breast cancer intratumour heterogeneity: current status and clinical implications. Histopathology 73(5):717-731. https://doi.org/10.1111/his.13642

39. Chibaudel B, Maindrault-Gœbel F, Bachet JB, Louvet C, Khalil A, Dupuis O, Hammel P, Garcia ML, Bennamoun M, Brusquant D, Tournigand C, Andre T, Arbaud C, Larsen AK, Wang YW, Yeh CG, Bonnetain F, de Gramont A (2016) PEPCOL: a GERCOR randomized phase II study of nanoliposomal irinotecan PEP02 (MM-398) or irinotecan with leucovorin/5-fluorouracil as 
second-line therapy in metastatic colorectal cancer. Cancer Med 5(4):676-683. https://doi.org/10.1002/cam4.635

40. Roy AC, Park SR, Cunningham D, Kang YK, Chao Y, Chen LT, Rees C, Lim HY, Tabernero J, Ramos FJ, Kujundzic M, Cardic MB, Yeh CG, de Gramont A (2013) A randomized phase II study of PEP02 (MM-398), irinotecan or docetaxel as a second-line therapy in patients with locally advanced or metastatic gastric or gastro-oesophageal junction adenocarcinoma. Ann Oncol 24(6):1567-1573. https://doi.org/10.1093/annonc/mdt002

41. Merrimack Pharmaceuticals Study of MM-398 with or without 5-FU/LV, versus 5-FU/LV in patients with metastatic pancreatic cancer (NAPOLI-1) (2016) ClinicalTrials.gov. https://clinicaltr ials.gov/ct2/show/results/NCT01494506. Accessed 23 Sept 2019

42. Bardia A, Mayer IA, Vahdat LT, Tolaney SM, Isakoff SJ, Diamond JR, O'Shaughnessy J, Moroose RL, Santin AD, Abramson VG, Shah NC, Rugo HS, Goldenberg DM, Sweidan AM, Iannone R,
Washkowitz S, Sharkey RM, Wegener WA, Kalinsky K (2019) Sacituzumab govitecan-hziy in refractory metastatic triple-negative breast cancer. N Engl J Med 380(8):741-751. https://doi. org/10.1056/NEJMoa1814213

43. Immunomedics, Inc. Prescribing Information (2020) TRODELVY ${ }^{\mathrm{TM}}$ (sacituzumab govitecan-hziy) for injection. US Food and Drug Administration. https://www.accessdata.fda.gov/ drugsatfda_docs/label/2020/761115s0001bl.pdf. Accessed 6 July 2020

Publisher's Note Springer Nature remains neutral with regard to jurisdictional claims in published maps and institutional affiliations.

\section{Affiliations}

\section{Jasgit C. Sachdev ${ }^{1,2}$ (1) $\cdot$ Pamela Munster ${ }^{3} \cdot$ Donald W. Northfelt ${ }^{4} \cdot$ Hyo Sook Han $^{5} \cdot$ Cynthia Ma $^{6} \cdot$ Fiona Maxwell . Tiffany Wang $^{8} \cdot$ Bruce Belanger $^{8} \cdot$ Bin Zhang $^{8} \cdot$ Yan Moore $^{8} \cdot$ Arunthathi Thiagalingam $^{8} \cdot$ Carey Anders $^{9}$}

\author{
Pamela Munster \\ Pamela.Munster@ucsf.edu \\ Donald W. Northfelt \\ Northfelt.Donald@mayo.edu \\ Hyo Sook Han \\ Hyo.Han@moffitt.org \\ Cynthia Ma \\ cynthiaxma@wustl.edu \\ Fiona Maxwell \\ fiona.maxwell@ipsen.com \\ Tiffany Wang \\ tiffany.wang@ipsen.com \\ Bruce Belanger \\ bruce.belanger@ipsen.com \\ Bin Zhang \\ bin.zhang@ipsen.com \\ Yan Moore \\ yan.moore@ipsen.com
}

Arunthathi Thiagalingam

arunthi.thiagalingam@ipsen.com

Carey Anders

carey.anders@duke.edu

1 HonorHealth Research Institute, 10510 N. 92nd Street, Suite 200, Scottsdale, AZ 85258, USA

2 Translational Genomics Research Institute, Phoenix, AZ, USA

3 University of California, San Francisco, CA, USA

4 Mayo Clinic Hospital, Phoenix, AZ, USA

5 Moffitt Cancer Center, Tampa, FL, USA

6 Washington University, St. Louis, MO, USA

7 Ipsen, Abingdon, UK

8 Ipsen, Cambridge, MA, USA

9 Duke Cancer Institute, Durham, NC, USA 